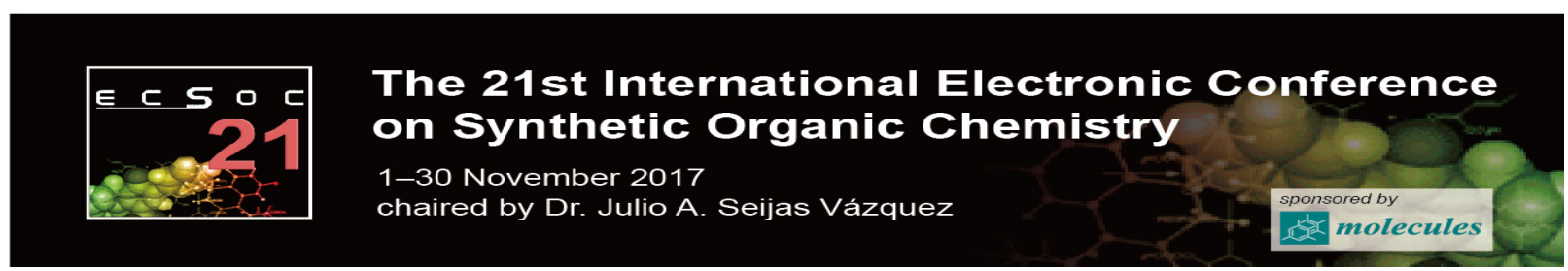

http://sciforum.net/conferencelecsoc-21

\title{
Oxidative bromination reaction using NBS and magnetic IBX
}

\author{
Nastaran Ghanbari, ${ }^{a}$ Hossein Ghafuri, ${ }^{\text {*a }}$ Hamid Reza Esmaili Zand ${ }^{\mathrm{a}}$ \\ ${ }^{a}$ Catalysts and Organic Synthesis Research Laboratory, Department of Chemistry, Iran \\ University of Science and Technology, Tehran, Iran \\ *E-mail: Ghafuri@iust.ac.ir
}

\begin{abstract}
Halogenated and brominated compounds are important groups of chemicals and have varied applications in several fields. Cross-coupling reactions in organic chemistry can be performed via aromatic functionalization process with halide aromatic compounds. Therefore, in coupling reactions like Heck, Suzuki, Sonogashira and hetero coupling reactions, halide compounds are the key fragments. $\mathrm{Br}_{2}$ is the old reagent for the formation of brominated compounds. Using $\mathrm{Br}_{2}$ caused to produce $\mathrm{HBr}$ as a corrosive chemical, need accurate control of temperature and control of amount of $\mathrm{Br}_{2}$. So, established better brominating agents have been developed in recent years. To this purpose, NBS was used for brominating reactions and several conditions in organic reactions have been reported to activate the halogenating ability of NBS. 2-iodoxybenzoic acid, IBX, has gained massive interest as an efficient and useful oxidant which can be used for the oxidation of alcohols. In addition of this, magnetic form of catalysts have more advantages compare to normal form of them due to their simply work-up procedures. So, to gain better nanocatalyst with the
\end{abstract}


advantages of magnetic catalysts, we used a simple method to prepare magnetized IBX. To develop efficient catalysts for oxidation reaction, we report the catalytic application of a magnetized IBX as an efficient and recoverable catalyst in the presence of NBS for oxidation reaction.

Keywords: Oxidative reaction, bromination reaction, NBS, magnetic IBX

\section{Introduction}

Halogenated compounds are significant categories of chemicals which have diverse applications in various fields. For the synthesis of brominated aromatic compounds, $\mathrm{Br}_{2}$ is the traditional reagent. Improved mild brominating agents with convenient usage have been developed in an organic solvent (1-8), but the fundamental disadvantage for most of these methods is unwanted oxidation of sensitive functional groups. To eliminate such problems, NBS was used for brominating the aromatic compounds. There is some reports that show the bromination and halogenation reaction in the presence of acidic and oxidation reagents (9). According to above description, it become obvious to us that when oxidation reagents and NBS come together, the results are far better in bromination reaction.

2-iodoxybenzoic acid, IBX, has gained massive interest as an efficient and useful oxidant which can be used for the oxidation of alcohols. In addition of this, magnetic form of catalysts have more advantages compare to normal form of them due to their simply work-up procedures. So, to gain better nanocatalyst with the advantages of magnetic catalysts, we used a simple method to prepare magnetized IBX. 
To this purpose, here the scope of magnetic IBX as a magnetic heterogeneous oxidation reagent in the presence of NBS was studied as a convenient and facile green synthesis of the corresponding brominated products of aryl alcohols. (Scheme 1).
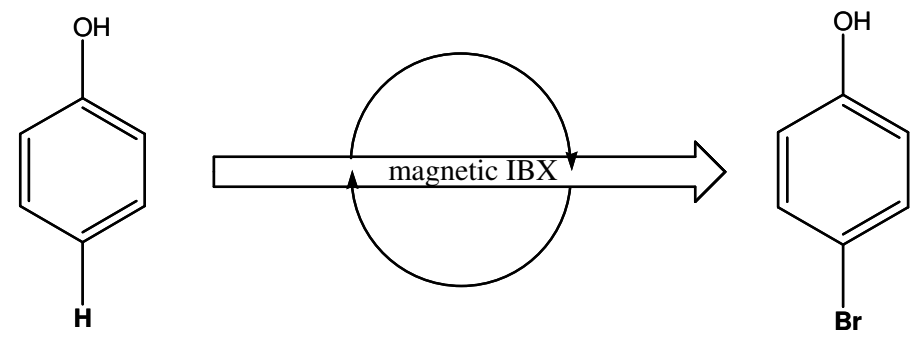

Scheme 1. Synthesis of aryl alcohols

\section{Experimental section}

\subsection{General}

Reagents and chemicals were all purchased from Aldrich, Merck and Fluka. Melting points were measured with an Electrothermal 9100 apparatus and are uncorrected. Spectra of FT-IR were recorded by the method of $\mathrm{KBr}$ pellet on a Shimadzu IR-470 spectrometer.

\subsection{General experimental procedure:}

$1 \mathrm{mmol}$ of phenol, $0.1 \mathrm{~g}$ NBS and $0.2 \mathrm{~g}$ catalyst were added to a flask. Reactions were conducted at room temperature in $\mathrm{EtOH}$ and the reaction was followed by TLC. After completion, the mixture was separated and catalyst was recovered. The recovered catalyst was reused five more times for the monobromination reaction without any decrease in its catalytic ability. 


\section{Results and discussion}

The monobromination reaction of aryl alcohols can be done by various phenols in optimized condition (table 1). The optimized conditions for the reaction was using $1 \mathrm{mmol}$ of phenol, $0.1 \mathrm{~g}$ NBS and $0.2 \mathrm{~g}$ catalyst.

Table 1. Monobromination of aryl alcohols

\begin{tabular}{|c|c|c|c|}
\hline Entry & Substrates & Products & $\begin{array}{c}\text { Yield of } \\
\text { products }\end{array}$ \\
\hline 1 & Phenol & 4-bromophenol & 93 \\
\hline 2 & 2,4-dichlorophenol & $\begin{array}{c}\text { 2-bromo-2,4- } \\
\text { dichlorophenol }\end{array}$ & 87 \\
\hline 3 & Benzaldehyde & 4-bromobenzaldehyde & 91 \\
\hline 4 & 2-chlorophenol & $\begin{array}{c}\text { 4-bromo-2- } \\
\text { chlorophenol }\end{array}$ & 85 \\
\hline 5 & 2-nitrophenol & $\begin{array}{c}\text { 4-bromo-2- } \\
\text { nitrophenol }\end{array}$ & 90 \\
\hline 6 & 2- & $\begin{array}{c}\text { 4-bromo-2- } \\
\text { hydroxybenzaldehyde }\end{array}$ & 88 \\
\hline
\end{tabular}

\section{Conclusion}

In summary, we used a magnetic IBX as a reagent in the presence of NBS for monobromination of aryl alcohols. We provide a simple and green method for this reaction in presence of environmentally friendly catalyst.

\section{Acknowledgements}

The authors gratefully acknowledge the partial support from the Research Council of the Iran University of Science and Technology. 


\section{References}

(1) Watano, S.; Okamoto, T.; Tsuhari, M.; Koizumi, I.; Osako, Y. Chem. Pharm. Bull. 2002, 50, 341.

(2) Trost, B. M.; Fleming, I. Comprehensive Organic Synthesis, Vol. 9, Cumulative Index, Pergamon, Oxford, 1991.

(3) B. Unterhalt, Methoden Org. Chemie (Houben-Weyl), Part 1, Vol. E14b, Thieme, Stuttgart, 1990, p. 387-433; M. Dumic, D. Koruncev, K. Kovacevic, L. Polak, D. Kolbah, Methoden Org. Chemie (Houben-Weyl), Part 1, Vol. E14b, Thieme, Stuttgart, 1990, p. 529-631.

(4) Tanaka, K. Solvent-free Organic Synthesis, Wiley-VCH, Weinheim, 2003, 240; Tanaka, K. Solvent-free Organic Synthesis, Wiley-VCH, Weinheim, 2003, 285; Tanaka, K. Solvent-free Organic Synthesis, Wiley-VCH, Weinheim, 2003, 291.

(5) Kad, G. L.; Bhandari, M.; Kau, J.; Rathee, R.; Singh, J. Green Chem. 2001, 3, 275.

(6) Sharghi, H.; Sarvari, M. H. J. Chem. Res., Synop. 2000, 24.

(7) Fazaeli, R.; Tangestaninejad, S.; Aliyan, H. Catal. Comm. 2006, 7, 205.

(8) Damljanovic, I.; Vukicevic, M.; Vukicevic, R. D. Wiener Mh. 2006, 137, 301.

(9) Shriner, R. L.; Hermann, C. K. F.; Morrill, T. C.; Curtin, D. Y.; Fuson, R. C. The Systematic Identification of Organic Compounds, 8th ed., Wiley, NewYork, 2003, p. 656. 